\title{
Pedagogical Considerations on the Senior Project Lab
}

\author{
JEFF HOOK
}

Two years ago, the CRP Department started to offer CRP 463 Senior Project Lab, as an option for students who, for different reasons, could not or decided not to take the two-quarter-long individually oriented and supervised senior project. Since then Jeff Hook has been teaching this lab, and brings us some comments on the student output and the importance of this capstone lab.

In planning education, as in life, one size doesn't fit all. Cal Poly's City and Regional Planning program "fits" students' diverse needs and learning styles through a new and flexible approach to completing Senior Project. To earn the Bachelor of Science degree in City and Regional Planning at Cal Poly, students must complete a senior project or thesis. The senior project is the culmination of the student's planning studies and represents the high-quality work expected of $4^{\text {th }}$ and $5^{\text {th }}$ year planning students about to enter the profession. In the past, students who chose to do a senior project had one option: to complete the senior project over two quarters, working with a faculty advisor who guides the student in what is, essentially, independent study. This approach has worked well for many students. For others, schedule conflicts or the need for more structured learning and faculty interaction made completing the traditional two-quarter senior project a daunting task.

Seniors now have another option for completing their senior project. It's called CRP 463, Senior Projects. It provides an alternative for students who choose to complete their senior project in one quarter, working in an intensive, highly-structured course format. As the capstone course in the undergraduate City and Regional Planning program, CRP 463 has two overarching objectives: (1) to apply planning theory and practice in solving problems related to the built environment through research, field studies and the preparation of project plans and supporting documents that meet senior project requirements, and (2) to develop skills and confidence in working under professional planning conditions, structure and standards.

\section{Jeff Hook}

AICP, Lecturer at the

City and Regional

Planning Department,

Cal Poly San Luis

Obispo. Senior

Planner, Community

Development, City of

San Luis Obispo.

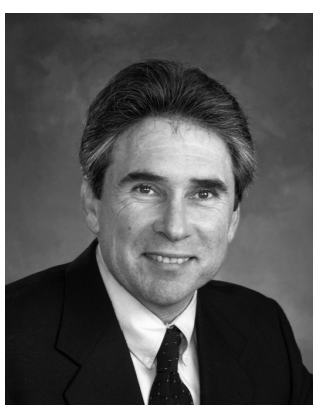

Figure 1

Sunset Medical Center, Dan Cermak and Dustin Emery; Spring 2007.

For the undergraduate student intent on finishing senior projectin one quarter, this is not an easy task. The course requires an extraordinary level of organization, time management and self-discipline to stay on schedule and meet course requirements. But, based on the results from "pilot" courses offered Spring Quarter 2006 and 2007, the benefits and the results are encouraging. Students were given a development site and chose their project from several potential development scenarios. They evaluated the site, researched case studies and served as "consultants" to provide the City with site analyses, conceptual and preliminary development plans, environmental studies and other

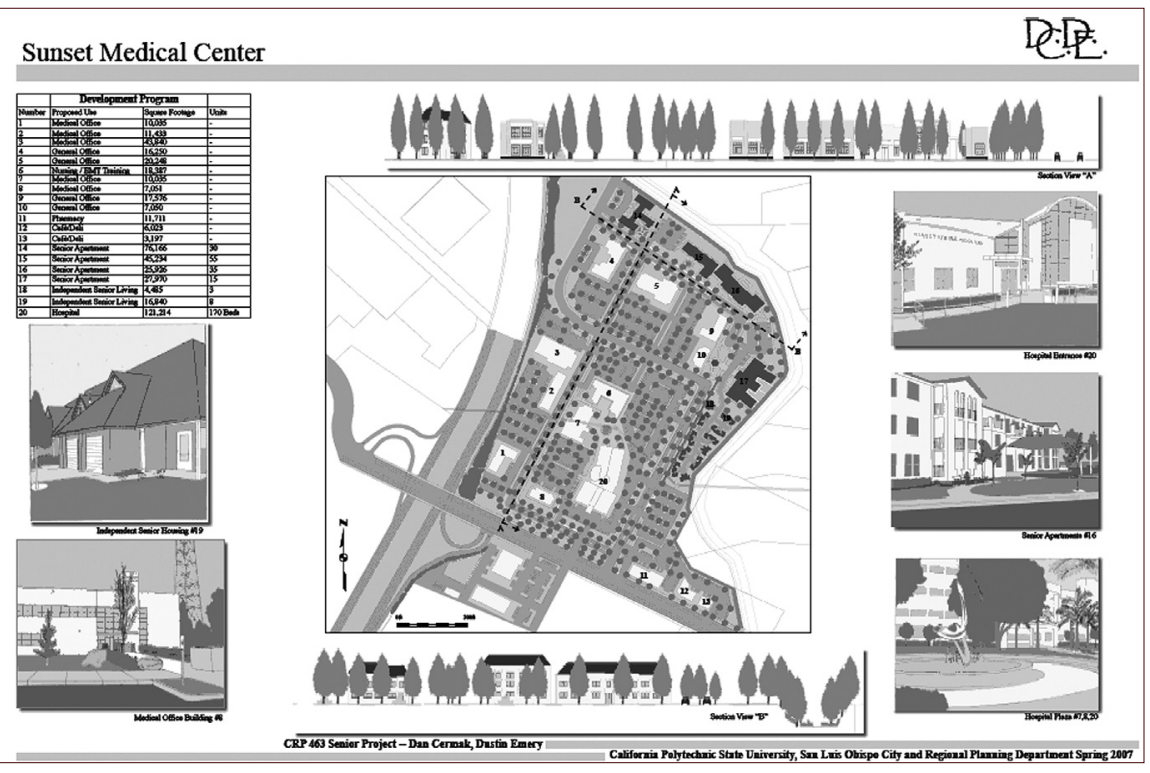
required deliverables. 
Professional quality work is the overarching goal. In 2006, students focused on the South Broad Street Corridor, a 135-acre site within the bounds of Broad Street, the railroad, South Street and Orcutt Road being considered by the City of San Luis Obispo for mixed-use infill development.

In 2007, students worked on the Sunset Drive-In property, a 50-acre site in San Luis Obispo near the intersection of Prado Road and State Highway 101. Each student signed a "consultant services contract" with the instructor and held "client meetings" every Thursday on a pre-determined schedule. Client meetings lasted 30 minutes and, at each, students were responsible for specific deliverables based on an approved workschedule.

For both sites, students completed a full range of planning studies and plans with either an environmental or urban design focus. Background research, site analyses, case studies, policy analysis, design exploration and synthesis and environmental review were used to support final recommendations presented in the final written project. Students then presented and defended their findings and recommendations at a meeting attended by students, faculty and community representatives. The

Figure 2

Broad Street Village Land Use and Circulation Plan,

Susanna Marcela Diaz and Valerie Ann Tallerico; following graphics give a taste of the high quality of the students' senior projects. Besides being the capstone experience of the students' formal planning education, CRP 463 may also be a springboard for their planning careers in "Life 101."

\section{BROAD STREAT VILLAGE LAND USE AND CIRCULATION PLAN}

WHY SHAPE A VILLAGE? -Villages can integrate social, environmental, and economic systems... They mix land uses, increase urban densities, encourage pedestrian travel, and are
to visit, work, and live in". The Case for Urban Villages. Randall Fleming, 1999

SITE AREA

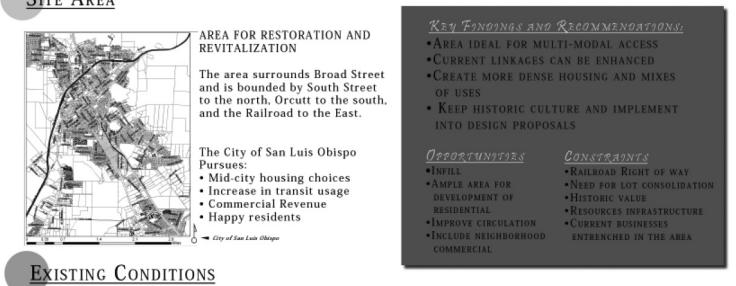

EXISTINg Conditions
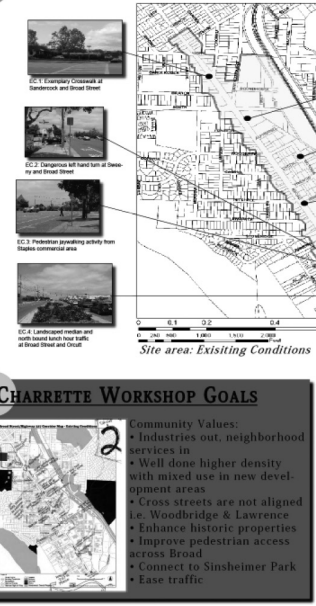
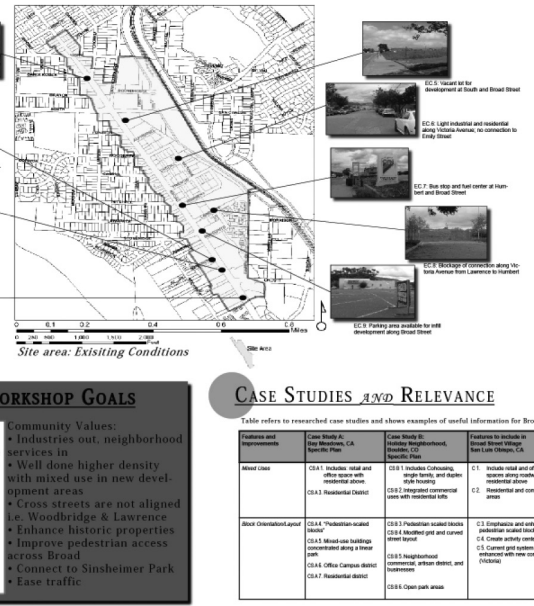

Case Studies and Relevance
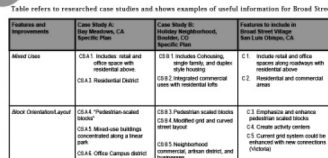

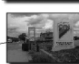

Land Use gind Circulation Plan
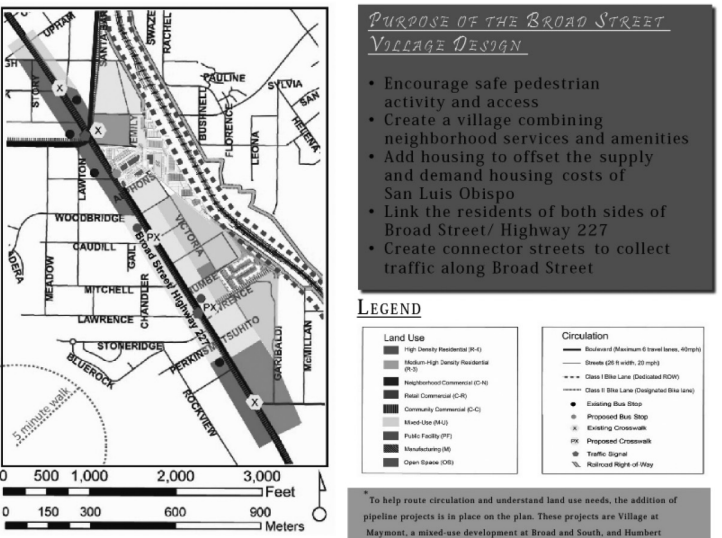

LEGEND

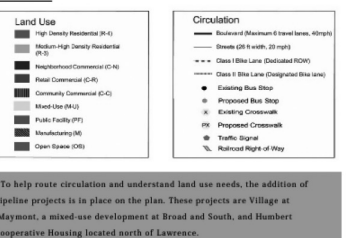

Alternative Plans
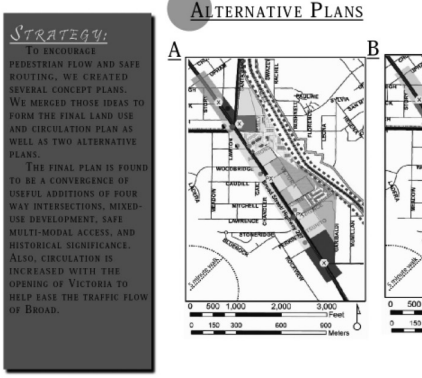

Cal Poly

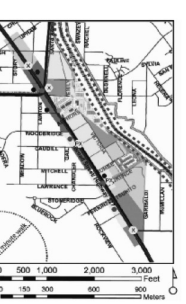

CITY \& REGIONAL
PLANNING

ResEARCHED AND
DESIGNED BY:

ResEarched AND
Designed By:

SusanNa DIAz \&
Valerie TaLLERIC

For: JefF Hook

\& THE CITY of
SAN LuIS OBIspo

JUNE 2006 